\title{
Expanding Access to Colorectal Cancer Screening: Benchmarking Quality Indicators in a Primary Care Colonoscopy Program
}

\author{
David A. McClellan, MD, Chinedum O. Ojinnaka, MBBS, MPH, Robert Pope, MD, \\ John Simmons, MD, Katie Fuller, DO, Andrew Richardson, MD, \\ Janet W. Helduser, MA, Phillip Nash, BSc, Marcia G. Ory, PhD, MPH, and \\ Jane N. Bolin, PhD, JD, BSN
}

Background: An inadequate supply of physicians who perform colonoscopies contributes to suboptimal screening rates, especially among the underserved. This shortage could be reduced if primary care physicians perform colonoscopies. This purpose of this article is to report quality indicators from colonoscopy procedures performed by family medicine physicians as part of a colorectal cancer prevention program targeting uninsured, low-income individuals.

Methods: A grant-funded colorectal cancer screening program was implemented to increase access to affordable colonoscopies for underinsured or uninsured residents of target counties while providing colonoscopy training to family medicine resident physicians. Colonoscopies were performed or supervised by 4 board-certified family physicians. Data were collected between 2011 and 2014.

Results: A total of 1155 colonoscopies were performed on 1101 individuals over a 3-year period. Cecal intubation rate was $\mathbf{9 6 . 2 5 \%}$. Adenoma detection rates among men and women $>50$ years old were $38.15 \%$ and $25.96 \%$, respectively. There was 1 perforation, which was referred to a hospital, and 1 instance of postprocedural bleeding, which spontaneously resolved.

Conclusions: Primary care physicians performing colonoscopies met the recommended quality indicators set forth by the American Society for Gastrointestinal Endoscopy. (J Am Board Fam Med 2015;28: 713-721.)

Keywords: Access to Health Care, Cancer, Prevention \& Control, Colonoscopy, Primary Health Care

Colonoscopy is an endoscopic procedure with a wide range of diagnostic and therapeutic indications and has become the most prevalent colorectal cancer (CRC) screening method in the United

This article was externally peer reviewed.

Submitted 18 December 2014; revised 24 June 2015; accepted 7 July 2015.

From the Department of Clinical \& Translational Medicine, College of Medicine, Texas A\&M University, Bryan (DAM, RP, JS, KF, AR); Texas A\&M Physicians Family Medicine Residency, Texas A\&M University, Bryan (DAM, RP, JS, KF, AR, PN); the Department of Health Policy and Management, School of Public Health, Texas A\&M University, College Station (COO, JWH, JNB); and the Department of Health Promotion and Community Health Sciences, School of Public Health, Texas A\&M University, College Station (MGO).

Funding: This publication was funded by the Cancer Prevention and Research Institute of Texas (CPRIT) (grant no. PP110176; program director/principal investigator: DAM; co-program director/co-principal investigator: JNB).

Conflict of interest: none declared.
States. ${ }^{1,2}$ It is one of the screening modalities recommended by expert organizations such as the American Cancer Society and the US Preventive Services Task Force for routine CRC screening starting at age $50 .{ }^{3-5} \mathrm{CRC}$ usually results from malignant transformation of adenomatous polyps that have resided in the large intestine for approximately 5 to 10 years. ${ }^{6}$ Thus, removal of polyps at an early stage is pivotal in CRC prevention. ${ }^{6}$ Colonoscopy has been identified as the most sensitive and 1 of the 2 most specific CRC screening modalities available. ${ }^{4}$ It is regarded as the gold standard for CRC screening

Corresponding author: Chinedum O. Ojinnaka, MBBS, MPH, Department of Health Policy and Management, Texas A\&M University School of Public Health, 1266 Adriance Lab Road, College Station, TX 77843-1266 (E-mail: ojinnaka@sph. tamhsc.edu). 
because it allows visualization of the entire colon with simultaneous detection and removal of polyps during the same procedure. ${ }^{7,8}$

Preference for either colonoscopy or fecal occult blood test (FOBT), another CRC screening modality, varies among patients and providers. Some studies have shown that both patients ${ }^{9,10}$ and physicians ${ }^{11,12}$ prefer colonoscopy over other recommended CRC screening methods, whereas other studies have shown a preference for FOBT or fecal immunochemical testing (FIT). ${ }^{14}$ Over the past decade, however, an increase in the use of screening colonoscopies has been observed, and these changes have contributed significantly to improved adherence to CRC screening guidelines. ${ }^{12,15,16} \mathrm{Al}$ though increased screening has been associated with a decline in CRC incidence, ${ }^{17,18} \mathrm{CRC}$ remains the third most common cause of cancer mortality when men and women are considered separately, and the second most common cause of cancer mortality for both men and women combined. ${ }^{19}$ It was estimated that 132,700 new cases of CRC would be diagnosed and 49,700 CRC-related deaths would occur in $2015 .^{20}$ The Centers for Disease Control and Prevention estimates that CRC-related mortality can be reduced by $60 \%$ if age-eligible adults adhere to screening recommendations. ${ }^{21}$ Identifying factors that hinder CRC screening is therefore a critical aspect of developing strategies to reduce or eliminate the impact of such obstacles to care.

Inadequate endoscopy capacity and insufficient numbers of physicians who perform endoscopy both contribute to suboptimal CRC screening rates. ${ }^{22-26}$ An increased density of primary care physicians and gastroenterologists in a given geographic region has been found to be inversely related to late-stage CRC diagnosis. ${ }^{27}$ Increasing the number of physicians who provide colonoscopies could improve CRC screening rates and reduce both CRC incidence (through early adenoma detection and removal) and later-stage diagnosis. The quality indicators recommended by the American Society for Gastrointestinal Endoscopy (ASGE) ${ }^{2}$ provide a benchmark for colonoscopy quality assessment. Using these benchmarks, colonoscopies performed by primary care physicians have produced results that are comparable to those of specialists. ${ }^{28}$ Therefore, equipping primary care physicians to provide colonoscopies could potentially increase CRC screening rates. However, funds needed to establish and equip clinical practices with colonoscopy equipment and trained personnel can be a challenge to the implementation of primary care colonoscopy. This purpose of this article is to report quality indicators from colonoscopy procedures performed by family medicine physicians as part of a CRC prevention program targeting uninsured, low-income individuals.

\section{Methods \\ Setting}

A university-affiliated family medicine center, home to a family medicine residency training program, has been conducting colonoscopies since 2004. The faculty physicians conducting and supervising the procedures are members of the American Association for Primary Care Endoscopy and, collectively, have 50 years of experience performing endoscopy. Colonoscopy training has been a standard part of the residency program's curriculum for family medicine resident physicians since 2004 .

The location for the current colonoscopy suite was planned as a part of the clinical space build-out of a procedure wing when the newly leased family medicine center was opened in 2011. However, the need for new colonoscopes and the cost of screening initially reduced the ability of the center to effectively provide CRC surveillance to residents of their target counties. In 2011, grant funds from the Cancer Prevention and Research Institute of Texas assisted the residency program in purchasing stateof-the-art equipment, including 3 colonoscopes enabled with jet irrigation, an endoscopy tower (computer and flat screen), an automatic endoscope washer, and a Simbionix GI-Bronch endoscopy simulator for training residency physicians under various simulation scenarios that might be encountered during patient care. The grant-funded CRC prevention program had 3 main objectives: (1) to educate community members about CRC and CRC screening recommendations, (2) to provide free colonoscopies to uninsured or underinsured residents of the target area, and (3) to provide colonoscopy training to family medicine resident physicians.

\section{Target Population}

The target area comprised 7 contiguous counties in central Texas. One of the counties is suburban, whereas 6 are rural. Between 2006 and 2011, 5 of these counties had higher CRC incidence rates and 
4 had higher CRC mortality rates compared with the state average. A community health assessment in 2010 revealed that nearly three quarters of the residents of the 7-county region were nonadherent to CRC screening guidelines. ${ }^{29}$ To effectively reach low-income and minority populations, bilingual community health workers were employed to provide culturally relevant community outreach and patient navigation services.

\section{Data Collection}

All patients consented to participation using the family medicine center's consent agreement form. Information on personal and family health history, such as previous CRC screening and family history of CRC, were collected using a questionnaire. Indications for the procedure were screening colonoscopy for asymptomatic individuals over age 50, individuals with a positive family history of adenomatous polyps or CRC, or symptoms concerning for CRC. ${ }^{2,30}$ Patients were evaluated for history of gastrointestinal bleeding, unexplained weight loss, and abdominal pain. Patients with ulcerative colitis or Crohn disease were referred to gastroenterologists for screening and surveillance. All patients undergoing CRC screening who noted a history of chronic diarrhea had random biopsies taken from the colon. Postpolypectomy follow-up and after-cancer surveillance practices were based on the consensus guideline from the American Cancer Society, US Multi-Society Task Force on Colorectal Cancer, and the American College of Radiology. ${ }^{30}$

All data were stored in the clinic's electronic health record, and a de-identified data set was provided by the clinic's information analyst to the investigators. The use of a de-identified data set from the colonoscopy procedures was approved by the institution's institutional review board (no. 2012-0583).

\section{Sedation}

Moderate sedation was used for all the colonoscopy procedures. Sedation was supervised by faculty physicians who were trained by endoscopy preceptors and obtained hospital privileges in moderate sedation through successful completion of an online credentialing module. Anesthesia was administered by either the nursing director of the procedure suite (a registered nurse who completed moderate sedation training) or resident physicians (who also completed moderate sedation training).
Patient vital signs, the electrocardiography/oximetry monitor, and level of consciousness were monitored throughout the procedure. A licensed nurse or medical assistant served as recorder. Moderate sedation was achieved using fentanyl and midazolam administration, starting with a test dose of 1 $\mathrm{mg}$ midazolam and $25 \mu \mathrm{g}$ fentanyl, with subsequent doses of either medication based on the patient's level of alertness (generally necessitating more midazolam) or level of pain (generally leading to additional fentanyl). Over the course of the grant, our institution developed and required sedation providers to pass an internal test that covers the approved sedation policy.

\section{Statistical Analyses}

Contingency tables for select patient characteristics by rural/urban residence were analyzed using $\chi^{2}$ or Fisher exact tests for categorical variables and $t$ test for age, which was a continuous variable. Because of insufficient numbers, the race/ethnicity categories were condensed as white, black/African American, Hispanic/Latino, and other. The "other" category comprised Asian, American Indian/Alaskan Native, or Native Hawaiian/Pacific Islander. Statistical significance for these analyses was established at $P<.05$. All analyses were conducted using Stata 13.1 (StataCorp, College Station, TX).

In concordance with the ASGE recommendations for colonoscopy quality indicators, we calculated the cecal intubation rate, adenoma detection rate, and average withdrawal time. ${ }^{2}$ Cecal intubation was determined by visualization of the appendiceal orifice, cecal trifolds, and ileocecal valve, with or without intubation of the terminal ileum. ${ }^{2,31}$ Photographic documentation of landmarks was performed for all procedures. Cecal intubation rate was calculated by dividing the number of procedures in which the cecum was attained by the total number of procedures performed. Adenoma and adenocarcinoma detection rates were calculated by dividing the total number of procedures, where adenomas or carcinomas were detected by the total number of procedures performed. Adenoma detection rates for men and women who are $\geq 50$ years old also were calculated.

\section{Results}

\section{Increased Access to Colonoscopies}

Over the 3-year period, 1101 individuals received 1155 colonoscopies. The age of participants who 
received free colonoscopies ranged from 17 to 85 years, with a mean age of 54.7 years. Among those older than 50 years, only about $36 \%$ had ever received a previous CRC screening. Table 1 displays the descriptive statistics of the patients by rural/ urban residence. Approximately $36 \%$ of patients were rural residents. A higher proportion of urban residents were Hispanic (43.74\%), whereas a higher proportion of rural residents were white (46.75\%) $(P=<.0001)$. A higher proportion of rural residents were uninsured compared with the proportion of uninsured urban residents $(86.58 \%$ vs $68.48 \% ; P=<.0001)$. Compared with urban residents, a higher proportion of rural residents reported a family history of adenomatous polyps or cancers $(33.23 \%$ vs $26.3 \% ; P=.001)$. A higher proportion of rural residents had been previously screened for CRC using FOBT or FIT $(24.90 \%$ vs $20.57 \% ; P=.016)$, whereas a higher proportion of urban residents had been screened for CRC using colonoscopy $(25.14 \%$ vs $22.04 \% ; P=.044)$. Among those who had a family history of CRC and who were also older than age 50, compared with rural residents, urban residents were more likely to report having a previous CRC screening using colonoscopy (45.74\% vs $28.26 \% ; P=.036$ ).

\section{Quality Indicators: C-STEP Compared with ASGE Recommendations}

Information on cecum attainment, adenoma detection, and withdrawal time were missing for 89 (7.7\%), 79 (6.9\%), and 132 procedures (11.4\%), respectively. Table 2 shows the quality indicator results in comparison to ASGE recommendations. All quality indicators met or exceeded the ASGE recommendations: cecal intubation rate was $96.25 \%$, average withdrawal time was 18.44 minutes, and overall adenoma detection rate was $27.3 \%$. A total of 840 colonoscopies were performed on those who were age 50 and older; 570 and 270 of these procedures were performed on women and men, respectively. Adenoma detection rates among men and women $>50$ years old were $38.15 \%$ and $25.96 \%$, respectively. The adenocarcinoma detection rate was $1.49 \%$. Of the 11 individuals who received a diagnosis of CRC, 9 were rural residents $(P=.003)$. There was one case of intestinal perforation, which was recognized during the procedure; the patient was promptly transferred to a nearby hospital and received adequate care. There was one reported case of postpolypectomy bleeding, which resolved spontaneously; thus the incidence of postpolypectomy bleeding was $0.09 \%$. One patient had sustained hypotension and hypoxia requiring the administration of reversal agents, which resulted in recovery without needing assisted ventilation.

\section{Discussion}

This study is based on an innovative strategy, that is, a partnership between a funding agency, an academic institution, and community organizations, resulting in access to colonoscopy for uninsured patients and enhanced endoscopy training opportunities for family medicine residents. Our results are consistent with those of previous studies in reporting that quality indicators from colonoscopies conducted by primary care physicians are comparable to those performed by specialists ${ }^{28,31-34}$ with respect to meeting the recommendations of the ASGE for safe and effective endoscopic surveillance for CRC. ${ }^{2,35}$

It is estimated that approximately $50 \%$ of colon cancers are located in the ascending or proximal part of the transverse colon and therefore cannot be detected by flexible sigmoidoscopy. ${ }^{6}$ It is recommended that individuals who have a positive FOBT/FIT receive a colonoscopy. ${ }^{4}$ Therefore, colonoscopy occupies a critical role in CRC prevention and early detection. Using National Health Interview Survey data, Haas et $\mathrm{al}^{22}$ found that increased availability of physicians who perform colonoscopies was associated with an increased number of screening colonoscopies performed. Haas et al also reported that living in counties with diminished capacity for colonoscopy had a marginal association with increased late-stage CRC at the time of diagnosis. Minority populations are more likely to reside in areas with an inadequate supply of gastroenterologists, ${ }^{22,36}$ and there is a persistent shortage of specialists, including gastroenterologists, in rural areas. ${ }^{33,37}$ Based on the above findings, minority and rural populations could be at increased risk for late-stage CRC diagnosis and poorer outcomes.

The finding in our study that rural residents were less likely to have been previously screened using colonoscopy, even among those who had a positive family history of CRC, could be a result of inadequate access to colonoscopy facilities in rural areas. We also found that most of the cancers were 


\begin{tabular}{|c|c|c|c|c|}
\hline & Urban $(\mathrm{n}=706)$ & Rural $(\mathrm{n}=389)$ & Total $(\mathrm{n}=1095)$ & $P$ Value \\
\hline Mean age (years) & 64.47 & 35.53 & & .57 \\
\hline Sex & & & & .644 \\
\hline Female & $497(70.40)$ & $279(71.72)$ & $776(70.87)$ & \\
\hline Male & $209(29.60)$ & $110(28.28)$ & $319(29.13)$ & \\
\hline Race/ethnicity & & & & .000 \\
\hline White & $191(27.48)$ & $180(46.75)$ & $371(34.35)$ & \\
\hline Black/African American & $165(23.74)$ & $81(21.04)$ & $246(22.78)$ & \\
\hline Hispanic/Latino & $304(43.74)$ & $113(29.35)$ & $417(38.61)$ & \\
\hline Other & $35(5.04)$ & $11(2.86)$ & $46(4.26)$ & \\
\hline Health insurance & & & & .000 \\
\hline No & $478(68.48)$ & $329(86.58)$ & $807(74.86)$ & \\
\hline Yes & $220(31.52)$ & $51(13.42)$ & $271(25.14)$ & \\
\hline \multicolumn{5}{|l|}{ Family history of adenomatous polyps or cancer } \\
\hline No & $336(70.15)$ & $188(58.93)$ & $524(65.66)$ & \\
\hline Yes & $126(26.30)$ & $106(33.23)$ & $232(29.07)$ & \\
\hline Unknown/don't know & $17(3.55)$ & $25(7.84)$ & $42(5.26)$ & \\
\hline \multicolumn{5}{|l|}{ Previous CRC screening using any test for among those above age 50} \\
\hline No & $338(64.38)$ & $184(58.79)$ & $522(62.29)$ & \\
\hline Yes & $184(35.05)$ & $116(37.06)$ & $300(35.80)$ & \\
\hline Unknown/don't know & $3(0.57)$ & $13(4.15)$ & $16(1.91)$ & \\
\hline Previous colonoscopy among those above age 50 & & & & .044 \\
\hline No & $384(73.14)$ & $230(73.48)$ & $614(73.27)$ & \\
\hline Yes & $132(25.14)$ & $69(22.04)$ & $201(23.99)$ & \\
\hline Unknown/don't know & $9(1.71)$ & $14(4.47)$ & $23(2.74)$ & \\
\hline $\begin{array}{l}\text { Previous Fecal Occult Blood Test (FOBT)/Fecal Immunochemical } \\
\text { Test (FIT) among those above age } 50\end{array}$ & & & & .016 \\
\hline No & $264(75.43)$ & $168(66.40)$ & $432(71.64)$ & \\
\hline Yes & $72(20.57)$ & $63(24.90)$ & $135(22.39)$ & \\
\hline Unknown/don't know & $14(4.00)$ & $22(8.70)$ & $36(5.97)$ & \\
\hline \multicolumn{5}{|l|}{$\begin{array}{l}\text { Previous CRC screening among those aged } \geq 50 \text { years who have a } \\
\text { positive family history }\end{array}$} \\
\hline No & $35(37.23)$ & $44(47.83)$ & $79(42.47)$ & \\
\hline Yes & $58(61.70)$ & $44(47.83)$ & $102(54.84)$ & \\
\hline Unknown/don't know & $1(1.06)$ & $4(4.35)$ & $5(2.69)$ & \\
\hline \multicolumn{5}{|l|}{$\begin{array}{l}\text { Previous colonoscopy among those aged } \geq 50 \text { years who have a } \\
\text { positive family history }\end{array}$} \\
\hline No & $47(50.00)$ & $62(67.39)$ & $109(58.60)$ & \\
\hline Yes & $43(45.74)$ & $26(28.26)$ & $69(37.10)$ & \\
\hline Unknown/don't know & $4(4.26)$ & $4(4.35)$ & $8(4.30)$ & \\
\hline $\begin{array}{l}\text { Previous FOBT/FIT among those age } 50 \text { and above who have a } \\
\text { positive family history }\end{array}$ & & & & .353 \\
\hline No & $58(62.37)$ & $51(57.30)$ & $109(59.89)$ & \\
\hline Yes & $30(32.26)$ & $28(31.46)$ & $58(31.87)$ & \\
\hline Unknown/don't know & $5(5.38)$ & $10(11.24)$ & $15(8.24)$ & \\
\hline \multicolumn{5}{|l|}{ Procedure results } \\
\hline Precursors & & & & .50 \\
\hline No & $499(73.82)$ & $283(72.01)$ & $782(73.15)$ & \\
\hline Yes & $177(26.18)$ & $110(27.99)$ & $287(26.85)$ & \\
\hline Cancer & & & & .003 \\
\hline No & $674(99.70)$ & $384(97.71)$ & $1058(98.97)$ & \\
\hline Yes & $2(0.30)$ & $9(2.29)$ & $11(1.03)$ & \\
\hline
\end{tabular}

Data are $\mathrm{n}(\%)$ unless otherwise indicated.

CRC, colorectal cancer; FOBT, fecal occult blood test; FIT, fecal immunochemical testing. 
detected among rural residents, which could be a result of inadequate prior access to screening and could suggest a need to improve the availability of CRC surveillance options for rural residents. However, further studies are needed to ascertain the availability of health care providers who are able to perform colonoscopies in our target counties and whether this is associated with inadequate screening adherence and detection at an advanced stage.

Office-based screening and surveillance colonoscopies have been found to be efficient, with quality indicators comparable to those performed in a hospital. ${ }^{38}$ Office-based colonoscopies are also a viable strategy for reducing long wait times for hospitalbased colonoscopies. ${ }^{38}$ Increasing the capacity of primary care physicians to perform colonoscopies could reduce delays in procedure scheduling. Delays in scheduling have been found to hinder the receipt of colonoscopy following positive FOBT. ${ }^{26,31}$ Patients $^{39}$ and physicians ${ }^{26}$ also identify delays as contributory to nonadherence to colonoscopy referral. Incorporating colonoscopy into primary care practices may have the added benefit of ensuring continuity of care, decreasing costs to patients, and decreasing transportation barriers (including travel time). ${ }^{40}$ Because a personal physician's recommendation is a strong predictor of CRC screening, ${ }^{41-44}$ and trust in a primary care physician is also associated with CRC screening compliance, ${ }^{13}$ primary care colonoscopy has great potential for decreasing CRC incidence

Table 2. Quality Indicators of Colonoscopy Procedures

\begin{tabular}{|c|c|c|}
\hline & Texas C-STEP & $\begin{array}{c}\text { ASGE } \\
\text { Recommendation }\end{array}$ \\
\hline Cecum attained, $\mathrm{n}(\%)$ & $1066(96.25)$ & $\geq 95 \%$ \\
\hline $\begin{array}{l}\text { Adenoma detection rate } \\
\text { among men and } \\
\text { women } \geq 50 \text { years } \\
\text { old, } \mathrm{n}(\%)\end{array}$ & $840(29.59)$ & \\
\hline $\begin{array}{l}\text { Adenoma detection rate } \\
\text { among women } \geq 50 \\
\text { years old, } \mathrm{n}(\%)\end{array}$ & $570(25.70)$ & $\geq 15 \%$ \\
\hline $\begin{array}{l}\text { Adenoma detection rate } \\
\text { among men } \geq 50 \\
\text { year, } \mathrm{n}(\%)\end{array}$ & $270(38.18)$ & $\geq 25 \%$ \\
\hline $\begin{array}{l}\text { Mean total withdrawal } \\
\text { time (minutes) }\end{array}$ & $1023(18)$ & $\geq 6$ minutes \\
\hline Perforation rate & $1155(1$ in 1155$)$ & 1 in 1000 \\
\hline $\begin{array}{l}\text { Post polypectomy } \\
\text { bleed, n (\%) }\end{array}$ & $1155(0.17)$ & $<1 \%$ \\
\hline
\end{tabular}

ASGE, American Society for Gastrointestinal Endoscopy; C-STEP, Cancer Screening, Training, Education and Program. and mortality. However, relatively few primary care physicians perform colonoscopies, ${ }^{23}$ and only a fraction of family medicine residencies train residents to conduct colonoscopies. ${ }^{41}$

We found that quality indicators from these primary care colonoscopies met or even exceeded ASGE recommendations and that this program enhanced overall access to colonoscopies for CRC screening for underserved patients. Endoscopy facilities affiliated with primary care residency programs could be another strategic way of increasing colonoscopy capacity. It has been reported that primary care residents who were trained to perform endoscopic procedures in a family medicine center are more likely to apply for credentialing to perform colonoscopies compared with those trained by specialists or in surgery clinics. ${ }^{45}$

An important goal of our CRC prevention program was to expand access to screening colonoscopy for low-income and uninsured residents. To achieve this purpose, partnerships were leveraged or developed between the residency program, the school of public health, local organizations, and safety-net health care providers that predominantly serve uninsured residents of the target counties. Self-referrals and referrals by health care providers were encouraged. Community outreach and community education were provided by community health workers. This enabled the participating physicians to focus on clinical management and performing the procedures.

Although the cost associated with colonoscopy programs could be a hindrance to primary care colonoscopy, this limitation could be resolved in part through strategic partnerships, similar to the one described here. The strategic partnership between the family medicine center and the funding agency provided the residency program with funds to purchase equipment needed for training. The school of public health was responsible for grant administrative requirements and outreach to inform community members and health care providers about the available services. This resulted in limited interference with clinical activities, and thus the physicians were able to focus on clinical management and performing the procedures. Such partnerships should be explored by other primary care residency programs. Collaborations between primary care residency programs that cannot afford to implement colonoscopy training and those who have colonoscopy training programs should also be explored as a cost-effective approach to colonos- 
copy training in primary care residency programs. Endoscopy centers that serve more than 1 primary care practice could also reduce or eliminate the barrier of cost for physicians who cannot afford to purchase colonoscopy equipment. ${ }^{46}$ Proactively increasing access to colonoscopy training among primary care physicians who belong to or serve minority groups should also be considered. This is highlighted in a study by Xirasagar et al, ${ }^{46}$ which found that, following colonoscopy training of African American primary care physicians, colonoscopy screening rates among African American patients in their practice increased, compared with both practice screening rates before training and screening rates of African American patients of primary care physicians in the area who were not trained in colonoscopy.

\section{Limitations}

The study had several limitations. First, it was conducted at 1 family medicine residency center; therefore, study findings might not be generalizable to other residency programs. In addition, this study is based on a program focused on colonoscopy training and could potentially bias resident physicians to recommending colonoscopy as the only screening modality. Despite these limitations, our study findings indicate that primary care colonoscopy in a family medicine residency achieves quality standards that are comparable to those of specialists and expands access to endoscopy training for resident physicians.

\section{Conclusion}

According to the Centers for Disease Control and Prevention, >30,000 CRC-related deaths could be prevented annually if everyone aged 50 and older adhered to screening guidelines. ${ }^{21}$ Approximately 28 million Americans are not up to date with CRC screening, ${ }^{21}$ despite increased recommendation for CRC screening by primary care physicians. ${ }^{12}$ Furthermore, it is projected that the increased influx of newly insured individuals into the health care system as a result of the Affordable Care Act will increase the demand for gastroenterology services, ${ }^{47}$ further decreasing endoscopy capacity. This situation may further pose a challenge to achieving the Healthy People 2020 screening target for CRC. It is therefore important to implement colonoscopy training in primary care residency programs as means of increasing the number of trained physicians who can perform colonoscopies. Since primary care physicians are more likely to practice in rural and less affluent areas than their specialist counterparts, ${ }^{48,49}$ training and equipping primary care physicians to perform colonoscopies should be explored as means of increasing colonoscopy capacity, especially among underserved populations.

\section{References}

1. Centers for Disease Control and Prevention (CDC). Vital signs: colorectal cancer screening test useUnited States, 2012. MMWR Morb Mortal Wkly Rep 2013;62:881-8.

2. Rex DK, Petrini JL, Baron TH, et al. Quality indicators for colonoscopy. Am J Gastroenterol 2006; 101:873-85.

3. Colorectal cancer prevention and early detection. Atlanta: American Cancer Society; 2015. Available from: http://www.cancer.org/cancer/colonandrectumcancer/ moreinformation/colonandrectumcancerearlydetection/ colorectal-cancer-early-detection-acs-recommendations. Accessed September 27, 2015.

4. U.S. Preventive Services Task Force. Screening for colorectal cancer: U.S. Preventive Services Task Force recommendation statement. Ann Intern Med 2008;149:627-37.

5. Smith RA, Cokkinides V, von Eschenbach AC, et al. American Cancer Society guidelines for the early detection of cancer. CA Cancer J Clin 2002; 52:8-22.

6. Townsend CM Jr, Beauchamp RD, Evers BM, Mattox KL (eds.). Sabiston textbook of surgery. the biological basis of modern surgical practice. Philadelphia: Elsevier; 2012.

7. Nicholson FB, Korman MG. Acceptance of flexible sigmoidoscopy and colonoscopy for screening and surveillance in colorectal cancer prevention. J Med Screen 2005;12:89-95.

8. Winawer SJ, Stewart ET, Zauber AG, et al. A comparison of colonoscopy and double-contrast barium enema for surveillance after polypectomy. National Polyp Study Work Group. N Engl J Med 2000;342: 1766-72.

9. Bosworth HB, Rockey DC, Paulson EK, et al. Prospective comparison of patient experience with colon imaging tests. Am J Med 2006;119:791-9.

10. Hawley ST, McQueen A, Bartholomew LK, et al. Preferences for colorectal cancer screening tests and screening test use in a large multispecialty primary care practice. Cancer 2012;118:2726-34.

11. Daskalakis C, Vernon SW, Sifri R, et al. The effects of test preference, test access, and navigation on colorectal cancer screening. Cancer Epidemiol Biomarkers Prev 2014;23:1521-8. 
12. Zapka J, Klabunde CN, Taplin S, Yuan G, Ransohoff D, Kobrin S. Screening colonoscopy in the US: attitudes and practices of primary care physicians. J Gen Intern Med 2012;27:1150-8.

13. Gupta S, Brenner AT, Ratanawongsa N, Inadomi JM. Patient trust in physician influences colorectal cancer screening in low-income patients. Am J Prev Med 2014;47:417-23.

14. Pignone MP, Crutchfield TM, Brown PM, et al. Using a discrete choice experiment to inform the design of programs to promote colon cancer screening for vulnerable populations in North Carolina. BMC Health Serv Res 2014;14:611.

15. Phillips KA, Liang SY, Ladabaum U, et al. Trends in colonoscopy for colorectal cancer screening. Med Care 2007;45:160-7.

16. Sinicrope PS, Goode EL, Limburg PJ, et al. A population-based study of prevalence and adherence trends in average risk colorectal cancer screening, 1997 to 2008. Cancer Epidemiol Biomarkers Prev 2012;21:347-50.

17. Edwards BK, Ward E, Kohler BA, et al. Annual report to the nation on the status of cancer, 1975-2006, featuring colorectal cancer trends and impact of interventions (risk factors, screening, and treatment) to reduce future rates. Cancer 2010;116:544-73.

18. Siegel RL, Ward EM, Jemal A. Trends in colorectal cancer incidence rates in the United States by tumor location and stage, 1992-2008. Cancer Epidemiol Biomarkers Prev 2012;21:411-6.

19. Siegel R, Desantis C, Jemal A. Colorectal cancer statistics, 2014. CA Cancer J Clin 2014;64:104-17.

20. Siegel RL, Miller KD, Jemal A. Cancer statistics, 2015. CA Cancer J Clin 2015;65:5-29.

21. "Screening for colorectal cancer: it's the right choice" infographic. Last reviewed September 20, 2013; last updated September 22, 2015. Atlanta: Centers for Disease Control and Prevention. Available from: http://www.cdc.gov/cancer/colorectal/ basic_info/screening/infographic.htm. Accessed September 27, 2015.

22. Haas JS, Brawarsky P, Iyer A, et al. Association of local capacity for endoscopy with individual use of colorectal cancer screening and stage at diagnosis. Cancer 2010;116:2922-31.

23. Brown ML, Klabunde CN, Mysliwiec P. Current capacity for endoscopic colorectal cancer screening in the United States: data from the National Cancer Institute Survey of Colorectal Cancer Screening Practices. Am J Med 2003;115:129-33.

24. Soneji S, Armstrong K, Asch DA. 2012. Socioeconomic and physician supply determinants of racial disparities in colorectal cancer screening. J Oncol Pract 2012;8:e125-34.

25. Seeff LC, Richards TB, Shapiro JA, et al. How many endoscopies are performed for colorectal cancer screening? Results from CDC's survey of endoscopic capacity. Gastroenterology 2004;127:1670-7.
26. Singh H, Khan R, Giardina TD, et al. Postreferral colonoscopy delays in diagnosis of colorectal cancer: a mixed-methods analysis. Qual Manag Health Care 2012;21:252-61.

27. Ananthakrishnan AN, Hoffmann RG, Saeian K. Higher physician density is associated with lower incidence of late-stage colorectal cancer. J Gen Intern Med 2010;25:1164-71.

28. Wilkins T, LeClair B, Smolkin M, et al. Screening colonoscopies by primary care physicians: a metaanalysis. Ann Fam Med 2009; 7:56-62.

29. Center for Community Health Development. 2010. Brazos Valley Health Assessment Executive Report. College Station, TX: School of Rural Public Health. Available from: http://www.hlth4all.org/Portals/47/ BV\%20Health\%20Assessment_ExecReport_2010. pdf. Accessed October 22, 2015.

30. Levin B, Lieberman DA, McFarland B, et al. Screening and surveillance for the early detection of colorectal cancer and adenomatous polyps, 2008: a joint guideline from the American Cancer Society, the US Multi-Society Task Force on Colorectal Cancer, and the American College of Radiology. CA Cancer J Clin 2008;58:130-60.

31. Kolber MR, Wong CK, Fedorak RN, Rowe BH; on behalf of the APC-Endo Study Physicians. Prospective study of the quality of colonoscopies performed by primary care physicians: the Alberta Primary Care Endoscopy (APC-Endo) Study. PLoS One 2013;8: e67017.

32. Azzopardi J, DeWitt DE. Quality and safety issues in procedural rural practice: a prospective evaluation of current quality and safety guidelines in 3000 colonoscopies. Rural Remote Health. 2012;12:1949.

33. Edwards JK, Norris TE. Colonoscopy in rural communities: can family physicians perform the procedure with safe and efficacious results? J Am Board Fam Pract 2004;17:353-8.

34. Xirasagar S, Hurley TG, Sros L, Hebert JR. Quality and safety of screening colonoscopies performed by primary care physicians with standby specialist support. Med Care 2010;48:703-9.

35. ASGE Standards of Practice Committee, Fisher DA, Maple JT, Ben-Menachem T, et al. Complications of colonoscopy. Gastrointest Endosc 2011; 74:745-52.

36. Hayanga AJ, Waljee AK, Kaiser HE, Chang DC, Morris AM. Racial clustering and access to colorectal surgeons, gastroenterologists, and radiation oncologists by African states: a county-level data analysis. Arch Surg 2009;144:532-5.

37. Aboagye JK, Kaiser HE, Hayanga AJ. Rural-urban differences in access to specialist providers of colorectal cancer care in the United States: a physician workforce issue. JAMA Surg 2014 Apr 16. [Epub ahead of print.]

38. Bair D, Pham J, Seaton MB, Arya N, Pryce M, Seaton TL. The quality of screening colonoscopies 
in an office-based endoscopy clinic. Can J Gastroenterol 2009;23:41-7.

39. Denberg TD, Melhado TV, Coombes JM, et al. Predictors of nonadherence to screening colonoscopy. J Gen Intern Med 2005;20:989-95.

40. Walker T, Deutchman M, Ingram B, Walker E, Westfall JM. Endoscopy training in primary care: innovative training program to increase access to endoscopy in primary care. Fam Med 2012;44: 171-7.

41. Wolf MS, Satterlee M, Calhoun EA, et al. Colorectal cancer screening among the medically underserved. J Health Care Poor Underserved 2006; 17:47-54.

42. Wong CR, Bloomfield ER, Crookes DM et al. Barriers and facilitators to adherence to screening colonoscopy among African-Americans: a mixedmethods analysis. J Cancer Educ 2013;28: 722-8.

43. Laiyemo AO, Adebogun AO, Doubeni CA, et al. Influence of provider discussion and specific recommendation on colorectal cancer screening uptake among U.S. adults. Prev Med 2014;67:1-5.

44. Underhill ML, Kiviniemi MT. The association of perceived provider-patient communication and relationship quality with colorectal cancer screening. Health Educ Behav 2012;39:555-63.

45. Wilkins T, Jester D, Kenrick J, Dahl J. The current state of colonoscopy training in family medicine residency programs. Fam Med 2004;36:407-11.

46. Xirasagar S, Hurley TG, Burch JB, Mansaray A, Hébert JR. Colonoscopy screening rates among patients of colonoscopy-trained African American primary care physicians. Cancer 2011;117:5151-60.

47. Sheen E. Supreme Court review of the Affordable Care Act: the future of health care reform and practice of gastroenterology. Dig Dis Sci 2012;57: 1735-41.

48. Rosenblatt RA. A view from the periphery - health care in rural America. N Engl J Med 2004;351: 1049-51.

49. Council on Graduate Medical Education. Council on Graduate Medical Education tenth report. Physician distribution and health care challenges in rural and inner-city areas. February 1998. Available from: http://www.hrsa.gov/advisorycommittees/bhpradvisory/ cogme/Reports/tenthreport.pdf. Accessed January 31, 2013. 